\title{
Epidemiology of acute kidney injury in Hungarian intensive care units: a multicenter, prospective, observational study
}

\author{
Laszlo Medve ${ }^{1}$, Csaba Antek², Balazs Paloczi ${ }^{2}$, Szilvia Kocsi ${ }^{3}$, Bela Gartner ${ }^{4}$, Zsuzsanna Marjanek ${ }^{5}$, Gabor Bencsik ${ }^{6}$, \\ Peter Kanizsai ${ }^{7}$ and Tibor Gondos ${ }^{*^{*}}$
}

\begin{abstract}
Background: Despite the substantial progress in the quality of critical care, the incidence and mortality of acute kidney injury (AKI) continues to rise during hospital admissions. We conducted a national, multicenter, prospective, epidemiological survey to evaluate the importance of AKI in intensive care units (ICUs) in Hungary. The objectives of this study were to determine the incidence of AKI in ICU patients; to characterize the differences in aetiology, illness severity and clinical practice; and to determine the influencing factors of the development of AKI and the patients' outcomes.
\end{abstract}

Methods: We analysed the demographic, morbidity, treatment modality and outcome data of patients $(n=459)$ admitted to ICUs between October $1^{\text {st }}, 2009$ and November $30^{\text {th }}, 2009$ using a prospectively filled in electronic survey form in 7 representative ICUs.

Results: The major reason for ICU admission was surgical in 64.3\% of patients and medical in the remaining $35.7 \%$. One-hundred-twelve patients (24.4\%) had AKI. By AKIN criteria 11.5\% had Stage 1,5.4\% had Stage 2 and 7.4\% had Stage 3. In $44.0 \%$ of patients, AKI was associated with septic shock. Vasopressor treatment, SAPS II score, serum creatinine on ICU admission and sepsis were the independent risk factors for development of any stage of AKI. Among the Stage 3 patients (34) 50\% received renal replacement therapy. The overall utilization of intermittent renal replacement therapy was high (64.8\%). The overall in-hospital mortality rate of AKI was 49\% (55/112). The ICU mortality rate was $39.3 \%$ (44/112). The independent risk factors for ICU mortality were age, mechanical ventilation, SOFA score and AKI Stage 3.

Conclusions: For the first time we have established the incidence of AKI using the AKIN criteria in Hungarian ICUs. Results of the present study confirm that AKI has a high incidence and is associated with high ICU and in-hospital mortality.

\section{Background}

Despite improvements in the quality of critical care, the incidence and mortality of acute kidney injury (AKI) continues to rise during hospital admission [1-3]. AKI has been the focus of numerous publications and research projects in the past 5 years. The incidence of AKI (during hospital admission) ranges from 3 to $25 \%$ depending on criteria applied. The variety of definitions used in clinical

\footnotetext{
* Correspondence: gondos.tibor@postino.hu

${ }^{8}$ Department of Oxyology and Emergency Care, Semmelweis University,

Faculty of Health Sciences, Vas u 17, Budapest, 1088, Hungary

Full list of author information is available at the end of the article
}

studies may be partially responsible for the large variations in the reported incidence and the associated mortality (19-83\%) of AKI [4-7]. Today the two widely accepted classification systems are the RIFLE criteria $[8,9]$ and the staging system for AKI as established by Acute Dialysis Quality Initiative (ADQI) and the Acute Kidney Injury Network (AKIN), respectively [10]. Understanding the changing spectrum of AKI is necessary to facilitate quality improvement efforts and to design successful epidemiological trials.

We have no controlled data about the epidemiology of AKI in critically ill patients in Hungary. The aims of our

\section{Biomed Central}

(c) 2011 Medve et al; licensee BioMed Central Ltd. This is an Open Access article distributed under the terms of the Creative Commons Attribution License (http://creativecommons.org/licenses/by/2.0), which permits unrestricted use, distribution, and reproduction in any medium, provided the original work is properly cited. 
study were to examine the incidence of AKI, to evaluate its impact, in the context of other risk factors, on outcomes (mortality, hospital- and ICU stay) and to compare the findings to the international experience.

\section{Methods}

\section{Study participants}

This study is a national, multicenter, prospective, epidemiological survey of AKI in 7 ICUs in Hungary. After ethical approval from each participating centre, we analysed demographic, morbidity and outcome data of 459 adult patients admitted to ICUs between October $1^{\text {st }}, 2009$ and November $30^{\text {th }}, 2009$. The participating centres represent the spectrum of Hungarian ICUs (each of them were multidisciplinary non-cardiac ICU, representing the occurrence ratio of ICU patients in Hungary): two university centres (University of Debrecen, University of Szeged), three regional hospitals (Petz Aladar County Hospital Gyor, Javorszky Odon Hospital Vac, Hetenyi Geza County Hospital Szolnok,) and two city hospital (Dr. Kenessey Albert Hospital Balassagyarmat, Szent Lukacs Hospital Dombovar). During the two months of the study, every newly admitted patient was registered in the survey and was followed up until hospital discharge or death in hospital.

Serum creatinine was determined at least once a day and urine output was recorded hourly, for all patients. AKI was defined and classified by the AKIN criteria [10], which has only three stages. Stage 1 is defined as an abrupt (within 48 hours) reduction in kidney function currently defined as an absolute increase in serum creatinine of more than or equal to $0.3 \mathrm{mg} / \mathrm{dl}(\geq 26.4 \mu \mathrm{mol} / \mathrm{l})$, a percentage increase in serum creatinine of more than or equal to $50 \%$ (1.5-fold from baseline), or a reduction in urine output (documented oliguria of less than $0.5 \mathrm{ml} / \mathrm{kg}$ per hour for more than six hours). Stage 2 is defined as doubling of serum creatinine or a urinary output lower than $0.5 \mathrm{ml} /$ $\mathrm{kg} / \mathrm{h}$ for $12 \mathrm{~h}$. Stage 3 is defined as tripling of serum creatinine or a serum creatinine higher than $4 \mathrm{mg} / \mathrm{dl}$ if there is an acute rise in serum creatinine of at least $0.5 \mathrm{mg} / \mathrm{dl}$, or a urinary output lower than $0.3 \mathrm{ml} / \mathrm{kg} / \mathrm{h}$ for $24 \mathrm{~h}$, or anuria for $12 \mathrm{~h}$. Stage 3 also includes patients who need renal replacement therapy, irrespectively of the stage they are in, at the time of renal replacement therapy.

Patients were categorized by serum creatinine and/or urine output into the AKIN stages and the highest AKIN stage during ICU staying was evaluated. Serum creatinine on ICU admission was used as a reference value, staging was based on the appropriate increase within the 48 hour observation. Declines in serum creatinine were not coded as AKI. Chronic kidney disease patients on dialysis $(n=3)$ and theoretically the renal transplant patients $(n=0)$ were excluded from the analysis. 12 patients had creatinine level
$>300 \mu \mathrm{mol} / \mathrm{L}$ on admission (severe AKI or unrecognized chronic renal failure). These patients were involved into the analysis.

\section{Data collection}

The Simplified Acute Physiology Score version II (SAPS II) [11] and the Sepsis-related Organ Failure Assessment Score (SOFA) [12] were used to evaluate severity of illness, and were calculated based on the worst variables recorded during the first 24 hours of ICU admission. The non-renal SOFA score was calculated from the total SOFA score minus the points for kidney insufficiency.

Multiple data were collected on each study participant, including: demographics, co-morbidities, hospital and ICU admission and discharge data, presumed aetiologies of AKI, surgical procedures, nonsurgical procedures, and renal replacement treatment modalities.

The aetiologies of AKI were identified from a group of seven possible choices (septic shock, hypovolemia, cardiogenic shock (these definitions were based on international guidelines), surgical procedure, obstructive nephropathies, drug-induced and others). Premorbid conditions were chosen from the following possibilities (medical or surgical admission; as well as cardiovascular, respiratory, gastrointestinal, neurological, and trauma diseases; malignancy, and others). More than one condition could be selected in each case.

The data were collected using an Excel-based data collection file. This was available to each participating centre with instructions. All centres were asked to complete the data entry and e-mail the data to the organisation centre. Upon arrival, all data were screened in detail by a dedicated intensive care specialist for any missing information, insufficient detail, or any other queries. Any queries generated an immediate e-mail inquiry with planned resolution within $48 \mathrm{~h}$.

\section{Statistical analysis}

All values were presented as mean values \pm SD or as median with interquartile range (IQR) as appropriate. The mean values of the different groups were compared using two-sided t-test, the median values by the Kolmogorov-Smirnov test and the occurrence rates by the chisquare test. A forward stepwise logistic regression analysis (conditional) was perform to determine the independent risk factors for AKI and mortality The included variables were: age, gender, vasopressor requirement, AKI stages, SOFA, SAPS II, creatinine level at ICU admission and the maximum level during ICU staying, surgical/medical admission, the different diseases, sepsis, mechanical ventilation, as appropriate. All variables were deemed to be significant if $p<0.05$. All analysis was performed by the SPSS statistical software package 15.0. 


\section{Results}

\section{Characteristics of the occurrence of AKI}

Altogether 459 patients (aged $59.6 \pm 16.2$ years, male/ female ratio 258/201) were entered into the study. Baseline characteristics of the patients are summarized in Table 1. Because there were no significant differences among the examined variables in respect of the gender, in the following analyses the data were drawn together. AKI patients $(\mathrm{n}=112)$ tended to be older $(64.9$ vs. 57.6 years, $\mathrm{p}<0.001$ ) and usually had more severe underlying diseases (SAPS II. 47.5 vs. 22 , p $<0.001$, SOFA 6 vs. 2 , $\mathrm{p}<0.001)$. The proportion of patients who needed mechanical ventilation during their ICU stay differed significantly in patients without or with AKI $33.4 \%$ and $75.0 \%, \mathrm{p}<0.001)$ A similar difference was also observed in the vasopressor needs $(12.1 \%$ vs. $51.8 \%$ in patients without and with AKI, respectively, $\mathrm{p}=0.0018$ ).

The incidence of AKI was $24.4 \%$. By AKIN criteria 53 patients (11.5\%) were in Stage 1, 25 patients (5.5\%) in Stage 2 and 34 patients (7.4\%) in Stage 3. Seventeen patients (15.2\% of the AKI cases) had received renal replacement therapy.

The major reason for ICU admission was surgical in 64.3\% (gastrointestinal tract surgery was the most common), followed by neurological, cardiovascular, pulmonary diseases and trauma cases (Table 2).

In $44.0 \%$ of patients, AKI was associated with septic shock (Figure 1). Sixteen percent of AKI was associated with major surgery, $20 \%$ was related to cardiogenic shock, $39 \%$ was related to hypovolemia, and $2 \%$ of AKI was potentially drug-related.

A logistic regression analysis was performed to analyse the predisposing factors for the incidence of AKI. Among the analysed parameters vasopressor treatment, SAPS II score, serum creatinine on ICU admission and sepsis were the independent risk factors for development of any stage of AKI (Table 3). The same distribution was found when the independent predisposing factors for AKI Stage 3 were evaluated.

\section{Renal replacement therapy}

Among AKI Stage 3 patients 50\% (17/34) received renal replacement therapy. The overall utilization of intermittent renal replacement therapy (IRRT) was high, with $64.8 \%$ (among all patients with RRT). All patients were treated with a veno-venous technique. The most common mode in the IRRT group was IHD (88\%) and in the CRRT group CVVHDF (94\%). The median filtration dose was a regimen of $20 \mathrm{~mL} / \mathrm{kg} / \mathrm{h}$.

\section{Mortality and lengths of stay}

The overall in-hospital mortality rate of AKI was 49.1\% (55/112). The ICU mortality rate was $39.3 \%(44 / 112)$ (Table 4). Any degree of AKI was associated with a significantly increased all-cause ICU (39.3\% vs. 9.5\%, p < $0.001)$ and overall mortality $(49.1 \%$ vs. $16.1 \%$ p $<0.001)$ compared with not having AKI. For patients admitted with AKI to the ICU, the median length of stay at the ICU increased by $120 \%$ ( 2 vs. 4.5 day, $\mathrm{p}<0.0001$ ) and the median length of hospitalization by $35 \%$ (10 vs. 13.5 day, $\mathrm{p}=0.005)$, compared to patient without AKI. According to the logistic regression analysis (Table 5) age, mechanical ventilation, SOFA score and AKI Stage 3 were found as independent risk factors for ICU mortality. In respect of the hospital mortality only the higher age, the need of vasopressor treatment and the neurological diseases were the independent risk factors for the mortality.

\section{Discussion}

The increased incidence of AKI is most likely due to a trend of admitting older, more severely and more chronically ill patients to hospitals [7,13-16]. Different studies describe a wide range of AKI (5.2\%-67.2\%) [14,17-19], which varies across intensive care units and admission diagnoses [20-25]. There are two studies which assessed the prevalence according to the AKIN criteria [14,19] and have found it between $22 \%-35.5 \%$, with different degrees of severity: AKI 1: 17.5\%-19.1\%, AKI 2: 2.4\%$3.8 \%$ and AKI 3: 2\%-12.5\%. Joannidis M and co-workers

Table 1 Characteristics of patients during ICU staying

\begin{tabular}{|c|c|c|c|c|}
\hline Parameters & All patient & AKI & non-AKI & p-AKI vs.non-AKI \\
\hline Patient number $\mathrm{n}(\%)$ & 459 & $112(24.4)$ & $347(75.6)$ & \\
\hline Age (year), mean \pm SD & $59.6 \pm 16.2$ & $64.9 \pm 14.4$ & $57.6 \pm 16.3$ & $<0001$ \\
\hline SAPS II. score, median (IQR) & $28(16,46)$ & $47.5(33,59)$ & $22(14,38)$ & $<0.001$ \\
\hline SOFA score, median (IQR) & $4(1,7)$ & $6(4,9.25)$ & $2(1,5.5)$ & $<0.001$ \\
\hline SOFA $_{\text {non renal, }}$ median $(\mathrm{IQR})$ & & $6(3,9)$ & & \\
\hline Se-creatinine at ICU admission ( $\mu \mathrm{mol} / \mathrm{L})$, median (IQR) & $76(59,103)$ & $117.5(81,205)$ & $70(57,87)$ & $<0.001$ \\
\hline Se-creatinine peak-concentration ( $\mu \mathrm{mol} / \mathrm{L})$, median $(\mathrm{IQR})$ & $80(61,112)$ & $165.5(112,274)$ & $71(58,89)$ & $<0.001$ \\
\hline Mechanical ventilation, $\mathrm{n}(\%)$ & $200(43.6)$ & $84(75)$ & $116(33.4)$ & $<0.001$ \\
\hline Ventilator days, median (IQR) & $3(1,7)$ & $3.5(2,11)$ & $2(1,7)$ & 0.177 \\
\hline Vasopressor treatment, n (\%) & $100(21.8)$ & $58(51.8)$ & $42(12.1)$ & 0.002 \\
\hline Vasopressor hours, median (IQR) & $49(24,96)$ & $48(24,99)$ & $63(18,92)$ & 0.619 \\
\hline
\end{tabular}


Table 2 Type and reason of ICU admissions

\begin{tabular}{|c|c|c|c|c|c|c|c|}
\hline \multirow[t]{2}{*}{ Reason for ICU admission } & \multirow{2}{*}{$\begin{array}{l}\text { All patient } \\
(n=459)\end{array}$} & \multirow{2}{*}{$\begin{array}{c}\text { non-AKI } \\
(n=347)\end{array}$} & \multicolumn{4}{|c|}{ Acute kidney Injury } & \multirow[t]{2}{*}{ p-AKI vs. non-AK } \\
\hline & & & $\begin{array}{l}\text { Stage } 1 \\
(n=53)\end{array}$ & $\begin{array}{l}\text { Stage } 2 \\
(n=25)\end{array}$ & $\begin{array}{l}\text { Stage } 3 \\
(n=34)\end{array}$ & $\begin{array}{c}\text { AKI all } \\
(n=112)\end{array}$ & \\
\hline Surgical & $295(64 \%)$ & $241(69 \%)$ & $27(24 \%)$ & $17(15 \%)$ & $10(9 \%)$ & $54(48 \%)$ & $<0.001$ \\
\hline Medical & $164(36 \%)$ & $106(31 \%)$ & $26(23 \%)$ & $8(7 \%)$ & $24(22 \%)$ & $58(52 \%)$ & \\
\hline Cardiovascular & $84(18 \%)$ & $60(17 \%)$ & $8(7 \%)$ & $6(5 \%)$ & $10(9 \%)$ & $24(21 \%)$ & 0.417 \\
\hline Respiratory & $67(15 \%)$ & $57(16 \%)$ & $6(5 \%)$ & 0 & $4(4 \%)$ & $10(9 \%)$ & 0.086 \\
\hline Malignancy & $126(27 \%)$ & $111(32 \%)$ & $9(8 \%)$ & $5(4 \%)$ & $1(1 \%)$ & $15(13 \%)$ & 0.002 \\
\hline Gastrointestinal & $135(29 \%)$ & $92(27 \%)$ & $20(18 \%)$ & $12(11 \%)$ & $9(8 \%)$ & $41(37 \%)$ & 0.136 \\
\hline Neurological & $85(19 \%)$ & $72(21 \%)$ & $11(10 \%)$ & $1(1 \%)$ & $1(1 \%)$ & $13(12 \%)$ & 0.067 \\
\hline Trauma surgery & $50(11 \%)$ & $42(12 \%)$ & $6(5 \%)$ & $1(1 \%)$ & $1(1 \%)$ & $8(7 \%)$ & 0.184 \\
\hline Others & $63(14 \%)$ & $42(12 \%)$ & $4(4 \%)$ & $7(6 \%)$ & $9(8 \%)$ & $20(18 \%)$ & 0.182 \\
\hline
\end{tabular}

Case numbers and percentage ratios, according to the appropriate groups.

analysed by AKIN criteria the SAPS 3 database, found the incidence $28.5 \%$, that is very similar to our data $(24.4 \%)$ [26]. While, they didn't found the difference between AKI 1 and 2, in our study AKI 1 (11.5\%) was double to AKI 2 (5.5\%). The difference may arise from the fact, that they assessing urine-output only at 24-hours intervals and could not distinguish between the AKIN stage 1 and 2. We found that the incidence of $7.4 \%$ in AKI 3 is better comparable to the data of Osterman [14] and Thakar [19], than the incidence of $13.8 \%$ of a cohort analysis [26].

We could demonstrate that the incidence rate of AKI is highest in elderly patients, who make up an ever-growing segment of the population. In the aging population, there is heightened susceptibility to drug toxicity, partially owing to altered drug pharmacokinetics and pharmacodynamics. Furthermore, elderly people consume twice as many medications overall, including nephrotoxic agents, than younger patients $[16,27]$. In our study, AKI patients were significantly older with significantly higher severity scores. We could prove that the higher SAPS II. score is an independent risk factor for AKI.

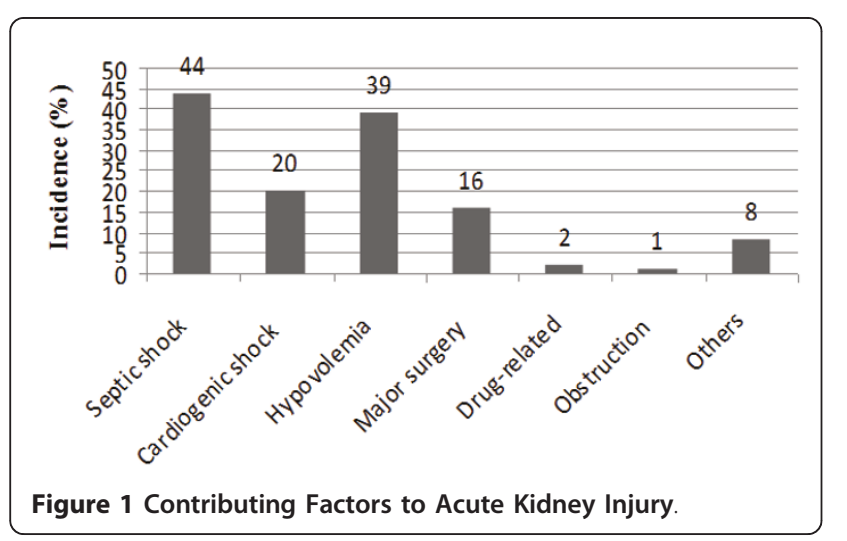

Renal dysfunction has a close association with the duration and weaning from mechanical ventilation [28]. Mechanical ventilation and vasopressor requirements were significantly higher in patients with AKI than in patients without AKI. Although, we could not distinguish that the mechanical ventilation or the vasopressor treatment was a cause or a consequent of AKI, we found a close relationship between them. Vasopressor treatment was a risk factor for the development of any stages of AKI, while mechanical ventilation was an independent risk factor for ICU mortality.

AKI has long been recognized as a devastating complication after surgery $[3,29]$ and postoperative AKI remains a leading cause of morbidity, mortality and prolonged hospital stay [18,21,29-32]. Despite the widespread recognition of increased risk for AKI following a variety of surgical procedures, the pathogenesis of this syndrome is poorly understood in all of these settings. We can estimate that approximately thirty percent of AKI was associated with abdominal surgery $[29,30]$. Inadequate renal perfusion pressure caused by complicated abdominal surgery is one of the key factors in the development of intraabdominal pressure (IAP)-induced kidney injury. Changes in IAP may have a great impact on renal function and urine output. Currently available data on AKI and its consequences suggest that AKI has the potential to substantially alter the outcome of patients with cancer [33]. The high incidence of abdominal surgery (37\%) and malignancy (13\%) in our patients with AKI indicates a major role of these conditions in the development of AKI.

The multicentre European Sepsis Occurrence in Acutely Ill Patients (SOAP) study [34] found that $51 \%$ of septic patients developed AKI. More recently, in a 1-day point prevalence survey for severe sepsis/septic shock from 454 ICUs in Germany, Oppert and co-workers [35] reported concomitant AKI in $41.4 \%$ of septic patients. 
Table 3 Stepwise logistic regression analysis of the variables for the incidence of AKI focused on AKI all and AKI Stage 3 versus non-AKI patients

\begin{tabular}{|c|c|c|c|c|c|c|c|c|}
\hline & \multirow[t]{2}{*}{ Variables } & \multirow[t]{2}{*}{ Coefficient } & \multirow[t]{2}{*}{ SE } & \multirow[t]{2}{*}{ Wald test } & \multirow[t]{2}{*}{$P$ value } & \multirow[t]{2}{*}{ Odds Ratio } & \multicolumn{2}{|c|}{$95 \% \mathrm{Cl}$} \\
\hline & & & & & & & lower & upper \\
\hline \multirow[t]{4}{*}{ AKI all } & Vasopressor treatment & 2.727 & 0.680 & 16.078 & $<0.001$ & 15.290 & 13.930 & 16.650 \\
\hline & SAPS II score & 0.040 & 0.017 & 5.554 & 0.018 & 1.041 & 1.007 & 1.075 \\
\hline & Se creatinine at ICU admission & 0.008 & 0.002 & 18.517 & $<0.001$ & 1.008 & 1.004 & 1.012 \\
\hline & Sepsis & 1.980 & 0.544 & 13.225 & $<0.001$ & 7.242 & 6.234 & 8.250 \\
\hline \multirow[t]{4}{*}{ AKI Stage 3} & Vasopressor treatment & 2.186 & 0.593 & 13.579 & $<0.001$ & 8.897 & 7.711 & 10.083 \\
\hline & SAPS II score & 0.018 & 0.008 & 5.694 & 0.017 & 1.018 & 1.002 & 1.034 \\
\hline & Se creatinine at ICU admission & 0.007 & 0.002 & 14.375 & $<0.001$ & 1.007 & 1.003 & 1.011 \\
\hline & Sepsis & 1.574 & 0.500 & 9.907 & 0.002 & 4.827 & 3.827 & 5.827 \\
\hline
\end{tabular}

SE, standard error; 95\% Cl, 95\% confidence interval.

Likewise, two large multicentre observational studies of critically ill patients with AKI found sepsis to be a contributing factor in $46 \%$ to $48 \%$ of episodes of AKI [3,35]. In our study, sepsis was also the leading etiologic factor (in $44 \%$ of patients) of AKI, and was a highly significant independent risk factor for AKI.

Cardiogenic shock associated renal hypoperfusion is strongly associated with AKI. The incidence of acute cardio-renal syndrome in patients with AKI is estimated to be between $19 \%$ and $45 \%$ [36]. In a large cohort study of patient after cardiac arrest [37], it was found that AKI occurs in nearly $50 \%$ of patients when the AKIN criteria were applied. This indicates that the severity of hypoxia/ischemia may also have an effect on the development of AKI. Marenzi et al [38] found that in the setting of ST-elevation acute myocardial infarction, complicated by cardiogenic shock, AKI occurred in $55 \%$ of patients. In our study $20 \%$ of AKI was related to cardiogenic shock.

Hypovolemia-associated prerenal failure, an important contributing factor to AKI was noted in $36 \%$ of our AKI patients. Since our study protocol did not require an invasive hemodynamic monitoring, we could not assess exactly the volume-status of patients on ICU-admission. We evaluated it as a major limitation of our study because the diagnosis of hypovolemia was based mainly on basic hemodynamic data and clinical impressions.
However, AKIN criteria do not determine specific diagnostic criteria to classify prerenal conditions. Because of the lack of standardized definitions and the difficulty in assessing reversibility of AKI, the concept of prerenal failure has been recently challenged [39].

It is known, that primary renal failure, secondary to a variety of pathologic conditions affecting the kidney, is usually treated in non-intensive care units and has relatively good prognosis and low mortality $(5-10 \%)[40,41]$. In contrast, the onset of AKI, as a part of multiple organ failure has 50-70\% mortality [5,18]. Osterman et al [14] report that applying AKIN criteria, the mortality of AKI is the following: AKI 1: 20.1\%, AKI 2: $25.9 \%$, AKI 3: $49.6 \%$. In our study the mortality was much higher: AKI all 41.3\%, AKI 1 35.8\%, AKI 2 44.0\%, AKI 3 73.5\%). The higher mortality of AKI in Hungarian ICUs can be explained also by factors, such as higher incidence of malignancy and non-uniform treatment principles. In the cohort analysis of Joannidis et al [26] 6.1\% of AKI was related to non-metastatic cancer patients, while in our study it was $13 \%$. The other reason may be that in Hungary there are not uniform protocols for treatment of AKI (different: the timing of RRT, the treatment modalities and doses of RRT, continuous vs. intermittent diuretic therapy). In our study the age, the sepsis related variables (vasopressor treatment, mechanical ventilation, SOFA score) and the AKI Stage 3 were

Table 4 Mortality and length of stay

\begin{tabular}{|c|c|c|c|c|c|c|c|}
\hline \multirow[t]{2}{*}{ Parameters } & \multirow{2}{*}{$\begin{array}{l}\text { All patients } \\
(n=459)\end{array}$} & \multirow{2}{*}{$\begin{array}{l}\text { non-AKI } \\
(n=347)\end{array}$} & \multicolumn{4}{|c|}{ Acute Kidney Injury } & \multirow[t]{2}{*}{ p-AKI all vs. non-AKI } \\
\hline & & & $\begin{array}{l}\text { Stage } 1 \\
(n=53)\end{array}$ & $\begin{array}{l}\text { Stage } 2 \\
(n=25)\end{array}$ & $\begin{array}{l}\text { Stage } 3 \\
(n=34)\end{array}$ & $\begin{array}{c}\text { AKI all } \\
(n=112)\end{array}$ & \\
\hline ICU-s stay (days), median (IQR) & $2(2,5)$ & $2(2,4)$ & $4(2,8)$ & $5(3,14)$ & $6(2,18)$ & $4.5(2,13)$ & $<0.001$ \\
\hline In-hospital stay (days), median (IQR) & $11(7,16)$ & $10(7,14)$ & $14(5,18)$ & $12(7,24)$ & $14(4,29)$ & $13.5(5,20)$ & 0.015 \\
\hline Overall mortality, n (\%) & $111(24.2)$ & $56(16.1)$ & 19 (35.9) & $11(44)$ & $25(73.5)$ & $55(49.1)$ & $<0.001$ \\
\hline ICU-s mortality, n (\%) & $77(16.8)$ & $33(9.5)$ & $14(26.4)$ & $10(40)$ & $20(58.8)$ & $44(39.3)$ & $<0.001$ \\
\hline In-hospital mortality after ICU, n (\%) & $34(7.4)$ & $23(6.6)$ & $5(9.4)$ & $1(4.0)$ & $5(14.7)$ & $11(9.8)$ & 0.301 \\
\hline
\end{tabular}


Table 5 Stepwise logistic regression analysis of the variables for the ICU and hospital mortality based on the total population

\begin{tabular}{ccccccccc}
\hline & Variables & Coefficient & SE & Wald test & P value & Odds Ratio & 95\% CI \\
\cline { 3 - 9 } & & & & & & lower & upper \\
\hline \multirow{2}{*}{ ICU mortality } & Age & 0.023 & 0.009 & 6.151 & 0.013 & 1.023 & 1.005 & 1.041 \\
\cline { 2 - 9 } & Mechanical ventilation & 1.976 & 0.371 & 28.382 & $<0.001$ & 7.217 & 6.475 & 7.959 \\
\cline { 2 - 9 } & SOFA & 0.212 & 0.042 & 25.572 & $<0.001$ & 1.236 & 1.152 & 1.320 \\
\cline { 2 - 9 } & AKI Stage 3 & 1.317 & 0.439 & 9.012 & 0.003 & 3.731 & 2.853 & 4.609 \\
\hline \multirow{2}{*}{ Hospital mortality } & Age & 0.052 & 0.021 & 6.335 & 0.012 & 1.053 & 1.011 & 1.094 \\
\cline { 2 - 9 } & Vasopressor treatment & 1.481 & 0.532 & 7.763 & 0.005 & 4.398 & 3.334 & 5.462 \\
\cline { 2 - 9 } & Neurological diseases & 1.416 & 0.707 & 4.018 & 0.045 & 4.122 & 2.708 & 5.536 \\
\hline
\end{tabular}

SE, standard error; $95 \% \mathrm{Cl}, 95 \%$ confidence interval.

the highly significant risk factors for the ICU and the hospital mortality.

The limitations of our study: Hypovolemia was not exclusion criteria in classification by AKIN. We applied early goal directed volume resuscitation, while followed the urine output hourly. If during the first six hours period the urine output raised above $0.5 \mathrm{ml} / \mathrm{kg} / \mathrm{h}$ we didn't classified the patient for AKI 1 stage. Secondly, the Hungarian ICU-s hasn't uniform protocol for treatment of AKI, so we couldn't compare the different ICU-s. Finally, we didn't distinguish early and late AKI.

\section{Conclusion}

We have conducted a national, multicenter, prospective, epidemiological study on AKI, occurring at representative Hungarian ICUs. For the first time, we have established the incidence of AKI using the AKIN criteria at Hungarian ICUs. The results of the present study confirm that AKI has a high incidence and is associated with higher ICU and in-hospital mortality. AKI doubles length of stay at the ICU and the duration of hospital staying. The independent risk factors for the development of any stage of AKI were SAPS II score, serum creatinine on ICU admission, sepsis and vasopressor treatment. Age, sepsis related variables (vasopressor treatment, mechanical ventilation, SOFA score) and AKI Stage 3 were the highly significant risk factors for the ICU and the hospital mortality.

\section{Abbreviations}

ADQI: Acute Dialysis Quality Initiative; AKI: acute kidney injury; AKIN: acute kidney injury network; CRRT: continuous renal replacement therapy; CWHDF: continuous veno-venous hemodiafiltration; ICU: intensive care unit; IHD: intermittent hemodialysis; IRRT: intermittent renal replacement therapy; RRT: renal replacement therapy; SAPS II: simplified acute physiology score; SOFA: sepsis-related organ failure assessment

\section{Author details}

${ }^{1}$ Department of Anaesthesiology and Intensive Care Medicine, Dr. Kenessey Albert Hospital, Rakoczi ut 125-127, Balassagyarmat, 2660, Hungary.

${ }^{2}$ Department of Anaesthesiology and Intensive Care Medicine, DEOC,

Nagyerdei krt 98, Debrecen, 4032, Hungary. ${ }^{3}$ Department of Anaesthesiology and Intensive Therapy, University of Szeged, Semmelweis ut 6, 6725, Szeged, Hungary. ${ }^{4}$ Department of Anaesthesiology and Intensive Care Medicine, Petz Aladar County Hospital, Vasvari Pal ut 2-4, 9023, Gyor, Hungary. ${ }^{5}$ Department of Anaesthesiology and Intensive Care Medicine, Javorszky Odon Hospital, Argenti Dome ter 1-3, Vac, 2600, Hungary. ${ }^{6}$ Department of Anaesthesiology and Intensive Care Medicine, Hetenyi Geza County Hospital, Toszegi ut 21, Szolnok, 5004, Hungary. ${ }^{7}$ Department of Anaesthesiology and Intensive Care Medicine, Szent Lukacs Hospital, Korhaz ut 39-41, Dombovar, 7200, Hungary. ${ }^{8}$ Department of Oxyology and Emergency Care, Semmelweis University, Faculty of Health Sciences, Vas u 17, Budapest, 1088, Hungary.

\section{Authors' contributions}

$M L, A C S, P B, K S Z, G B, M Z S, B G$ and KP collected the data, ML and GT drafted the manuscript. GT performed the statistical analysis. All authors read and approved this manuscript.

\section{Competing interests}

The authors declare that they have no competing interests.

Received: 11 September 2010 Accepted: 13 September 2011 Published: 13 September 2011

\section{References}

1. Mehta RL, Pascual MT, Soroko S, Savage BR, Himmelfarb J, Ikizler TA, Paganini EP, Cherto GM: Spectrum of acute renal failure in the intensive care unit: The PICARD experience. Kidney International 2004, 66:1613-1621.

2. Uchino S, Bellomo R, Morimatsu H, Morgera S, Schetz M, Tan I, Bouman C, Macedo E, Gibney N, Tolwani A, Oudemans-van Straaten H, Ronco C, Kellum JA: Continuous renal replacement therapy: A worldwide practice survey. The Beginning and Ending Supportive Therapy for the Kidney (B.E.S.T. Kidney) Investigators. Intensive Care Med 2007, 33:1563-1570.

3. Bagshaw SM, George C, Bellomo R: Early acute kidney injury and sepsis: a multicentre evaluation. Critical Care 2008, 12:R47.

4. Pisoni R, Wille KM, Tolwani AJ: The epidemiology of severe acute kidney injury: from BEST to PICARD, in acute kidney injury: new concepts. Nephron Clin Pract 2008, 109:188-91.

5. Silvester W, Bellomo R, Cole L: Epidemiology, management, and outcome of severe acute renal failure of critical illness in Australia. Crit Care Med 2001, 29:1910-5.

6. Vincent $J$ : Incidence of acute renal failure in the intensive care unit. Contrib Nephrol 2001, 132:1-6.

7. De Mendonca A, Vincent JL, Suter PM, Moreno R, Dearden NM, Antonelli M, Takala J, Sprung C, Cantraine F: Acute renal failure in the ICU: risk factors and outcome evaluated by the SOFA score. Intensive Care Med 2000, 26:915-921.

8. Mehta RL, Kellum JA, Shah SV, Molitoris BA, Ronco C, Warnock DG, Levin A, for the Acute Kidney Injury Network: Acute Kidney Injury Network: report of an initiative to improve outcomes in acute kidney injury. Critical Care 2007, 11:R31.

9. Hoste EAJ, Clermont G, Kersten A, Venkataraman R, Angus DC, Bacquer D, Kellum JA: RIFLE criteria for acute kidney injury are associated with hospital mortality in critically ill patients: a cohort analysis. Critical Care 2006, 10:R73. 
10. Kellum JA, Bellomo R, Ronco C: Definition and classification of acute kidney injury. Nephron Clin Prac 2008, 109:c182-7.

11. Le Gall JR, Lemeshow S, Saulnier F: A new Simplified Acute Physiology score (SAPS II) based on a European/North American multicenter study. JAMA 1993, 270:2957-63.

12. Vincent $J$, Moreno R, Takala J, Willats S, De Mendoca A, Bruining H, Reinhard CK, Suter PM, Thijs LG: The SOFA(Sepsis-related Organ Failure Assessment) score to describe organ dysfunction/failure. On behalf of the Working Group on Sepsis-Related Problems of the European Society of Intensive Care Medicine. Intensive Care Medicine 1996, 22:707-10.

13. Kolhe NV, Stevens PE, Crowe AV, Lipkin GW, Harrison DA: Case mix, outcome and activity for patients with severe acute kidney injury during the first 24 hours after admission to an adult, general critical care unit: application of predictive models from a secondary analysis of the ICNARC Case Mix Programme Database. Critical Care 2008, 12:S2.

14. Ostermannw M, Chang R: Riyadh ICU Program Users Group Crit Care. Correlation between the AKI classification and outcome. Critical Care 2008, 12:R144

15. Cole L, Bellomo R, Silvester W, Reeves $J H$ : A prospective, multicenter study of the epidemiology, management, and outcome of severe acute renal failure in a 'closed' ICU system. Am J Respir Crit Care Med 2000, 162:191-196.

16. Coca SG: Acute kidney injury in elderly persons. Am J Kidney Dis 2010, 56:122-31.

17. Hoste EA, Kellum JA: Incidence, classification, and outcomes of acute kidney injury. Contrib Nephrol 2007, 156:32-8.

18. Ali T, Khan I, Simpson W, Prescott G, Townend J, Smith W, Macleod A: Incidence and outcomes in acute kidney injury: a comprehensive population-based study. J Am Soc Nephrol 2007, 18:1292-8.

19. Thakar CV, Christianson A, Freyberg R, Almenoff P, Render ML: Incidence and outcomes of acute kidney injury in intensive care units: a Veterans Administration study. Crit Care Med 2009, 37:2552-8

20. Lopes JA, Fernandes P, Jorge S, Goncalves S, Alvarez A, Costa e Silva Z, Franca C, Prata MM: Acute kidney injury in ICU patients: a comparison between RIFLE and AKIN. Critical Care 2008, 12:R110.

21. Waikar SS, Liu KD, Chertow GM: Diagnosis, epidemiology and outcomes of acute kidney injury. Clin J Am Soc Nephrol 2008, 3:844-861.

22. Cruz DN, Ronco C: Acute kidney injury in the intensive care unit: current trends in incidence and outcome. Critical Care 2007, 11:149.

23. Keyes R, Bagshaw SM: Early diagnosis of acute kidney injury in critically ill patients. Expert Rev Mol Diagn 2008, 8:455-64.

24. Kellum JA, Hoste EA: Acute kidney injury: epidemiology and assessment. Scand J Clin Lab Invest 2008, 24(Suppl):6-11.

25. Ricci Z, Cruz D, Ronco C: The RIFLE criteria and mortality in acute kidney injury: A systematic review. Kidney Int 2008, 73:538-46.

26. Joannidis M, Metnitz B, Bauer P, Schusterschitz N, Moreno R, Druml W, Metnitz PGH: Acute kidney injury in critically ill patients classified by AKIN versus RIFLE using the SAPS 3 database. Intensive Care Med 2009, 35:1692-1702.

27. Himmelfarb J: Acute kidney injury in the elderly: problems and prospects. Semin Nephrol 2009, 29:658-64.

28. Vieira JM, Castro I, Curvello-Neto A, Demarzo S, Caruso P, Pastore L, Imanishe MH, Abdulkader RCRM, Deheinzelin D: Effect of acute kidney injury on weaning from mechanical ventilation in critically ill patients. Critical Care Medicine 2007, 35:184-191.

29. Abelha FJ, Botelho M, Fernandes $V$, Barros $H$ : Determinants of postoperative acute kidney injury. Critical Care 2009, 13:R79.

30. Chertow GM, Burdick E, Honour M, Bonventre JV, Bates DW: Acute kidney injury, mortality, length of stay, and costs in hospitalized patients. J Am Soc Nephrol 2005, 16:3365-71.

31. Bihorac A, Schold JD, Hobson CE: Long-term mortality associated with acute kidney injury requiring dialysis. JAMA 2010, 303:229-30.

32. Murray $P$ : Who is at increased risk for acute kidney injury following noncardiac surgery? Critical Care 2009, 13:171.

33. Lameire N, Van Biesen W, Vanholder R: Acute renal problems in the critically ill cancer patient. Curr Opin Crit Care 2008, 14:635-46.

34. Vincent JL, Sakr Y, Sprung CL, Ranieri VM, Reinhart K, Gerlach H, Moreno R, Carlet J, Le Gall JR, Payen D: Sepsis in European intensive care units: results of the SOAP study. Crit Care Med 2006, 34:344-353.

35. Oppert M, Engel C, Brunkhorst FM, Bogatsch H, Reinhart K, Frei U, Eckardt KU, Loeffler M, John S: Acute renal failure in patients with severe sepsis and septic shock a significant independent risk factor for mortality: results from the German Prevalence Study. Nephrol Dial Transplant 2008, 23:904-909.

36. Ronco C, McCullough P, Anker SD, Anand I, Aspromonte N, Bagshaw SM, Bellomo R, Berl T, Bobek I, Cruz DN, Daliento N, Davenport A, Haapio M, Hillege $H$, House AA, Katz N, Maisel A, Mankad S, Zanco P, Mebazaa A, Palazzuoli A, Ronco F, Shaw A, Sheinfeld G, Soni S, Vescovo G, Zamperetti N, Ponikowski P, for the Acute Dialysis Quality Initiative (ADQI) consensus group: Cardio-renal syndromes: report from the consensus conference of the Acute Dialysis Quality Initiative. Eur Heart J 2010, 31:703-711.

37. von Haehling Stephan, Storm C, Jörres A, Schefold JC: Changes in serum creatinine in the first 24 hours after cardiac arrest indicate prognosis: an observational cohort study. Critical Care 2009, 13:R168.

38. Marenzi G, Assanelli E, Campodonico J, De Metrio M, Lauri G, Marana I, Moltrasio M, Rubino M, Veglia F, Montorsi P, Bartorelli AL: Acute kidney injury in ST-segment elevation acute myocardial infarction complicated by cardiogenic shock at admission. Crit Care Med 2010, 38:438-44.

39. Macedo E, Mehta RL: Prerenal failure: from old concepts to new paradigms. Curr Opin Crit Care 2009, 15:467-73.

40. Barrantes F, Feng Y, Ivanov O, Yalamanchili HB, Patel J, Buenafe X, Cheng V, Dijeh S, Amoateng-Adjepong $Y$, Manthous CA: Acute kidney injury predicts outcomes of non-critically ill patients. Mayo Clin Proc 2009, 84:410-6.

41. VA/NIH Acute Renal Failure Trial Network: Intensity of renal support in critically ill patients with acute kidney injury. NEJM 2008, 359, (Suppl. Appendix).

\section{Pre-publication history}

The pre-publication history for this paper can be accessed here: http://www.biomedcentral.com/1471-2369/12/43/prepub

doi:10.1186/1471-2369-12-43

Cite this article as: Medve et al:: Epidemiology of acute kidney injury in Hungarian intensive care units: a multicenter, prospective, observational study. BMC Nephrology 2011 12:43.

\section{Submit your next manuscript to BioMed Central and take full advantage of:}

- Convenient online submission

- Thorough peer review

- No space constraints or color figure charges

- Immediate publication on acceptance

- Inclusion in PubMed, CAS, Scopus and Google Scholar

- Research which is freely available for redistribution

Submit your manuscript at www.biomedcentral.com/submit
C Biomed Central 